\title{
Avaliação de qualidade das águas superficiais no lago da barragem de Três Marias-MG
}

\section{Ciro Couto Bento ${ }^{1}$ Gustavo Filemon Costa Lima ${ }^{2}$ Hernando Baggio Filho ${ }^{1}$ Adolf Heinrich Horn ${ }^{2}$}

${ }^{1}$ Universidade Federal dos Vales de Jequitinhonha e Mucuri (UFVJM) Programa de Pós-Graduação em Geologia Campus Juscelino Kubitschek, Diamantina, MG Brazil CEP $39.100-000$

${ }^{2}$ Universidade Federal de Minas Gerais Instituto de Geociências Instituto de Geociências
Departamento de Geologia Departamento de Geologia Belo Horizonte MG Brazil CEP 31207-901

* Autor correspondente ciro.bento@gmail.com

\section{RESUMO}

O presente trabalho apresenta uma análise geoquímica ambiental da água superficial para a identificação de contaminação do lago da Barragem da Usina Hidrelétrica de Três Marias da CEMIG, localizada na parte centro-norte de Minas Gerais. Tem como proposta avaliar a situação ambiental que se encontra a água superficial da área de estudo, considerando as particularidades naturais e as características antrópicas da região. Este lago abrange oito municípios situados entre os paralelos $19,05^{\circ} \mathrm{S}$ e $18,20^{\circ} \mathrm{S}$ e os meridianos $44,95^{\circ} \mathrm{W}$ e $45,50^{\circ} \mathrm{W}$. A amostragem de águas superficiais foi feita em julho de 2018 em 58 pontos, distribuídos ao longo do segmento fluvial represado pela barragem hidrelétrica. Analisaram-se os parâmetros químicos totais (detergente; sulfato; amônia; nitrito; nitrato; alumínio; zinco; ferro; manganês; boro) e os parâmetros físico-químicos in situ (temperatura, $\mathrm{pH}$, condutividade elétrica, oxigênio dissolvido, total de sólidos dissolvidos, turbidez, cor aparente). Os resultados foram comparados aos limites estabelecidos pela Resolução do Concelho Nacional de Meio Ambiente (CONAMA) 357/05 e Portaria do Ministério da Saúde (MS) n518. Alguns resultados obtidos estão no limite dos valores estabelecidos pela legislação, outros ultrapassam o limite, mostrando o potencial de suscetibilidade ambiental da área. Destaca-se negativamente a concentração do Alumínio que ultrapassou em todos os pontos o limite legal. As concentrações do sulfato e dos compostos nitrogenados não ultrapassaram as concentrações dos limite normativos. Quanto aos parâmetros in situ, somente o oxigênio dissolvido apresentou em desconformidade com as normas.

Palavras-chave: Geoquímica ambiental, Mina do Feijão, Usina Hidrelétrica de Três Marias, Rio São Francisco, Rio Paraopeba

\section{ABSTRACT}

The present work provides an environmental geochemical analysis of surface water for the identification of contamination of the lake of the Dam of the Hydroelectric Plant of Três Marias of CEMIG, located in the central-north part of Minas Gerais. Its proposal is to evaluate the environmental situation found in the surface water of the study area, considering the natural particularities and the anthropic characteristics of the region. This lake covers eight municipalities located between the $19.05^{\circ} \mathrm{S}$ and $18.20^{\circ} \mathrm{S}$ parallels and the $44.95^{\circ} \mathrm{W}$ and 45.50 ${ }^{\circ} \mathrm{W}$ meridians. Surface water sampling was carried out in July 2018 at 58 points, distributed along the river segment dammed by the hydroelectric dam. Total chemical parameters were analyzed (detergent; sulfate; ammonia; nitrite; nitrate; aluminum; zinc; iron; manganese; boron) and the physical-chemical parameters in situ (temperature, $\mathrm{pH}$, electrical conductivity, dissolved oxygen, total dissolved solids, turbidity, apparent color). The results were compared to the limitas established by the Resolution of the National Environment Council (CONAMA) 357/05 and Ordinance of the Ministry of Health (MS) No. 518. Some results obtained are within the limits of the values established by legislation, others exceed the limit, showing the potential for environmental susceptibility of the area. The aluminum concentration that exceeded the legal limit in all points stands out negatively. The concentrations of sulfate and nitrogen compounds did not exceed the concentrations of the normative limits. Regarding the parameters in situ, only dissolved oxygen presented non-compliance with the standards.

Keywords: Environmental geochemistry, Feijão Mine, Três Marias Hydroelectric Power Plant, São Francisco River, Paraopeba River 


\section{INTRODUÇÃO}

O Rio São Francisco tem projeção nacional como importante reserva de recursos hídricos, suas águas são utilizadas tanto para importantes atividades econômicas, tais como agricultura, pecuária, piscicultura ou geração de energia elétrica, quanto para o uso pessoal dos habitantes que o margeiam. Além disso, muitas espécies da fauna $\mathrm{e}$ flora são diretamente dependentes das águas do rio. Desta forma o conhecimento da qualidade destas águas é decisivo para um manejo e abastecimento da população com eficiência e sustentabilidade. De forma intrínseca, a qualidade da água de um rio, no que se refere à responsabilidade antrópica, está ligada ao uso e ocupação da terra na área da bacia hidrográfica. Assim sendo, a ocupação dos espaços que margeiam os rios é concomitantemente uma ação dependente da qualidade da água e um processo de interferência desta mesma qualidade. Portanto, essa dualidade da ocupação da terra remete à importância do constante monitoramento dos parâmetros indicadores de qualidade da água (VON SPERLING 2014a).

A análise da qualidade da água perpassa por três grupos principais de parâmetros: os físico-químicos; químicos; biológico (VON SPERLING, 2014b). Nesse aspecto os parâmetros físico-químicos exercem fundamental importância, pois $\mathrm{o}$ acompanhamento dessas variáveis consegue ser, operacionalmente, simples e rápido. Além disso, a alteração de um ambiente devido algum contaminante decorre de resposta imediata nos parâmetros físico-químicos. Em contra partida, os parâmetro de concentração de elementos químicos são categoricamente taxativos sobre a qualidade da água, denunciando a presença ou ausência de determinado contaminante. (BAIRD et al., 2008).

A Portaria $\mathrm{N}^{\circ} 2914$ de 12 de Dezembro de 2011 do Ministério da Saúde dispõe sobre os

\section{1 ÁREA DE ESTUDO}

A área de estudo está localizada, segundo a divisão do Instituto Brasileiro de Geografia e Estatística (IBGE), dentro de duas Regiões Geográficas Intermediárias de Minas Gerais, a Região de Belo Horizonte e de Divinópolis. O trabalho foi realizado no lago próximo às cidades de Três Marias, São Gonçalo do Abaeté, Felixlândia, Morada Nova de procedimentos de controle e de vigilância da qualidade da água para o consumo humano e seu padrão de potabilidade. Contíguo à portaria, a Resolução do Conselho de Meio Ambiente - CONAMA N ${ }^{\circ} 357$ de 17 de Março de 2005, especifica a classificação dos corpos de água dividindo-os em diversas classes conforme o seu uso. A partir destes dados essa legislação define diretrizes para o seu enquadramento, como estabelece as condições e padrões para lançamento de efluentes.

Historicamente a região de Três Marias foi submetida a diversas atividades antropogênicas que podem ocasionar perturbações aos ecossistêmicas da região. Sendo assim, esse trabalho tem como objetivo avaliar a composição química e, a partir destes dados, a qualidade da água do lago da barragem da Usina Hidrelétrica de Três Marias da Companhia Elétrica de Minas Gerais CEMIG, localizada na parte central-norte de Minas Gerais.

Desde os anos 90 uma série de estudos geoquímicos foram realizados neste lago com o intuito de caracterizar e monitorar a concentração e dinâmica de contaminantes (OLIVEIRA; HORN, 2006; OLIVEIRA, 2007; BAGGIO, 2008; RIBEIRO, 2010; TRINDADE, 2010; HORN et al. 2014). Em 25 de Janeiro de 2019 ocorreu o rompimento da barragem de rejeitos da Mina do Feijão (Brumadinho/MG), acidente no qual lançou grande quantidade de rejeito no Rio Paraopeba. Sendo a barragem de Três Marias o local do encontro do Rio Paraopeba com o Rio São Francisco, para entender as consequências desse acidente no Rio São Francisco é necessário conhecer a qualidade da água do Lago de Três Marias antes do acidente da Mina do Feijão. Portanto, para além das variações espaciais e temporais dos contaminantes no lago, o trabalho permite levantar um Background das consequências da tragédia de Brumadinho no Rio São Francisco.

Minas, Biquinhas, Paineiras, Abaeté e Pompeu (Figura 1). A área estudada é de aproximadamente $1000 \mathrm{~km}^{2}$, iniciando na barragem da hidrelétrica, localizada nas coordenadas (UTM/WGS-84 zona 23k) 472292E/7986170S, e seguindo a montante do rio cerca de 100 quilômetros. 


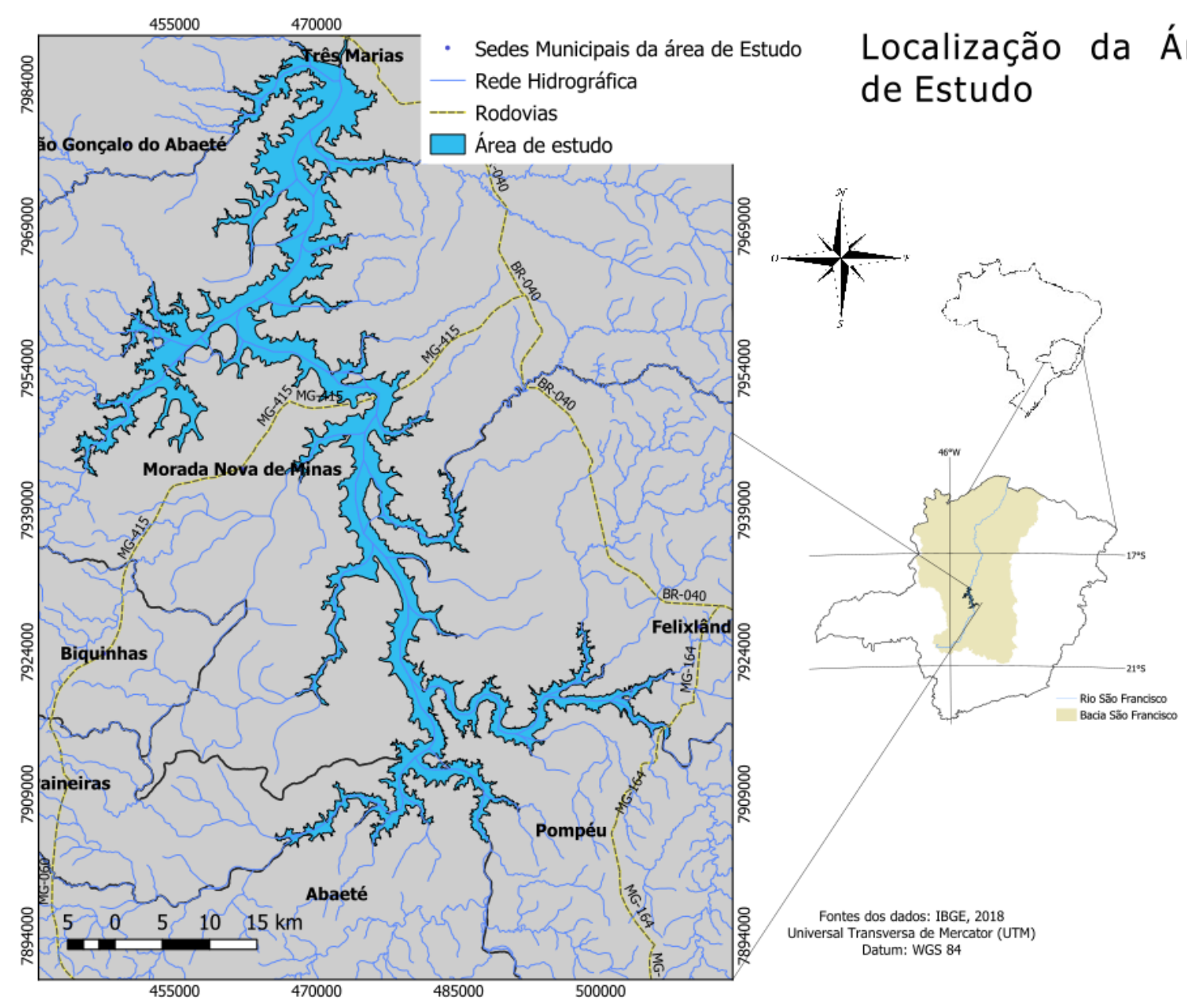

Figura 1 Localização da área de estudo.

\subsection{HIDROGRAFIA}

A bacia do Rio São Francisco foi compartimentada em quatro áreas segundo a Agência Nacional das Águas (ANA, 2019), sendo o Alto São Francisco da nascente até Pirapora; o Médio São Francisco de Pirapora ao Lago Sobradinho; o Submédio São Francisco de Remanso a Paulo Afonso e, por fim, o Baixo São Francisco de Paulo Afonso até a foz. Assim sendo a área estudada situa-se dentro da bacia hidrográfica do Alto São Francisco (Figura 2).

A bacia hidrográfica do Rio São Francisco é a maior bacia brasileira exclusivamente nacional. Corresponde a cerca de $8 \%$ do território nacional totalizando uma área de drenagem de cerca de $639.217 \mathrm{~km}^{2}$, segundo o Comitê da Bacia Hidrográfica do Rio São Francisco (CBHSF, 2016). Este rio nasce na Serra da Canastra em Minas Gerais e deságua no Oceano Atlântico na divisa entre os estados de Alagoas e Sergipe, em um percurso de
$2.700 \mathrm{~km}$. O curso do rio segue na direção NS da nascente até o norte do estado da Bahia onde toma direção SE e assim segue até à foz, passando por cinco estados federativos do Brasil. A zona de influência da área de estudo está situada no Alto São Francisco, com destaque para a região metropolitana da Grande Belo Horizonte.

A área da bacia hidrográfica que contribui ao reservatório de Três Marias é de aproximadamente $50.782,7 \mathrm{~km}^{2}$, sendo o extremo topográfico mais alto com altitude de cerca de $1.400 \mathrm{~m}$, e a cota mais baixa com valores e cerca de $500 \mathrm{~m}$. O reservatório tem um barramento concretado de cerca de $3 \mathrm{~km}$ de extensão e a área de espelho de água é de cerca de $1.050 \mathrm{~km}^{2}$. O volume de água pode chegar, no período de cheia, a 21 bilhões de $\mathrm{m}^{3}$. A direção do curso d'água se desenvolve no sentido aproximado de sul para norte tendo como principais cursos d'água contribuintes do 
lago o Rio São Francisco, Rio Paraopeba, Rio Para, Rio Borrachudo, Rio Indaiá, Ribeirão da Estrema, Ribeirão do Boi, Córrego do Tronco,
Córrego Jataí, Córrego Forquilha, Córrego Ponte de Pedra e Córrego do Estêvão (Figura 2).

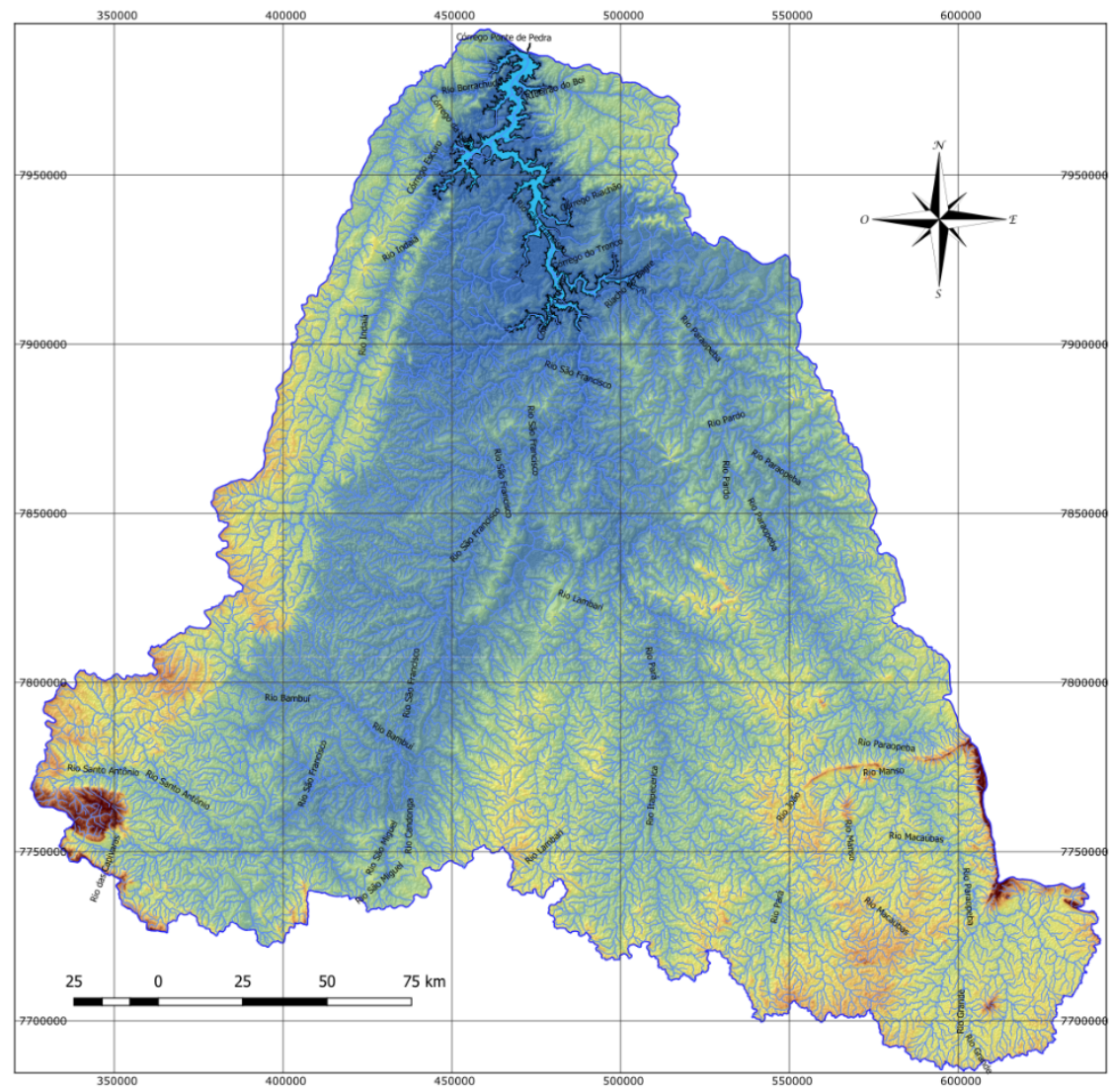

Mapa Hipsométrico

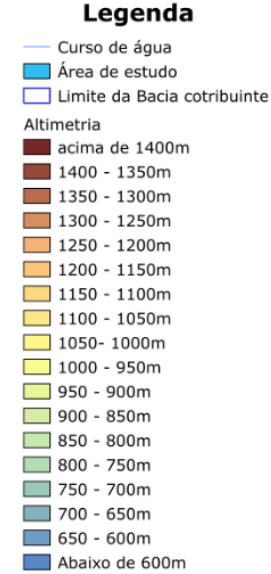

Mapa hipsométrico da bacia contribuinte a área de estudo, com a rede de drenagem e a identificação dos principais rios, ribeirões e córregos.

\subsection{GEOLOGIA}

A bacia Sanfranciscana abrange mais de $300.000 \mathrm{~km}^{2}$ e representa uma bacia intracratônica que recobre o embasamento do Cráton do São Francisco. As litologias aflorantes nesta região correspondem a associações rochosas neoproterozóicas do Grupo Bambuí ou a uma pequena porção de rochas do cretáceo Grupo Areado (COSTA et al., 2011). $\mathrm{Na}$ área de estudo ocorrem somente três formações do Grupo Bambuí: Formação Lagoa do Jacaré; Formação Serra da Saudade; Formação Três Marias(TRINDADE, 2010).

A Formação Lagoa do Jacaré é a unidade discretamente representada na área, composta por calcários, siltitos e margas ; (IGLESIAS; UHLEIN, 2009; FRAGOSO et al., 2011). A

\subsection{USO E OCUPAÇÃO DO SOLO}

A população residente no entorno do lago, de acordo com o censo de 2010, é de 116.014 habitantes distribuídos entre 8 municípios,
Formação Serra da Saudade é representada por uma sucessão de siltitos e arenitos impuros com nítido aspecto de ritmitos (FRAGOSO et al. 2013). Sobreposta encontra a Formação Três Marias. Esta tem como característica sedimentos de composição quase que exclusivamente de arcósias muito impuras de uma coloração cinza esverdeada (COSTA et al.2011).

O Grupo Areado é representado por afloramentos de conglomerados basais da Formação Abaeté, sobrepostos a esses observa-se sedimentos lacustres da Formação Quiricó e, por vezes, acompanhado de arenitos bem selecionado da Formação Três Barras (IGLESIAS; UHLEIN 2009).

sendo que a densidade demográfica é de 7,85 $\mathrm{hab} / \mathrm{km}^{2}$ (IBGE). A cidade de Três Marias é a maior cidade que margeia o rio. 
As principais atividades econômicas observadas nas margens do lago são plantação de monocultura de eucalipto, plantação de soja e arroz, pecuária, piscicultura e hotelaria com atracadouros para pesca e banhos recreativos.

Segundo os dados de cobertura da terra do IBGE de 2012 e do INPE de 2013, os principais usos do solo da região são agricultura e silvicultura, seguidos de pastagens natu- rais e plantadas (Figura 3). Segundo os mesmos dados as áreas de vegetação natural se restringem à área da estação ecológica Pirapitinga do ICMBio (Instituto Chico Mendes de Conservação da Biodiversidade), às matas ciliares preservadas na margem do rio e ao mosaico de vegetação campestre associada $\mathrm{a}$ áreas agrícolas.

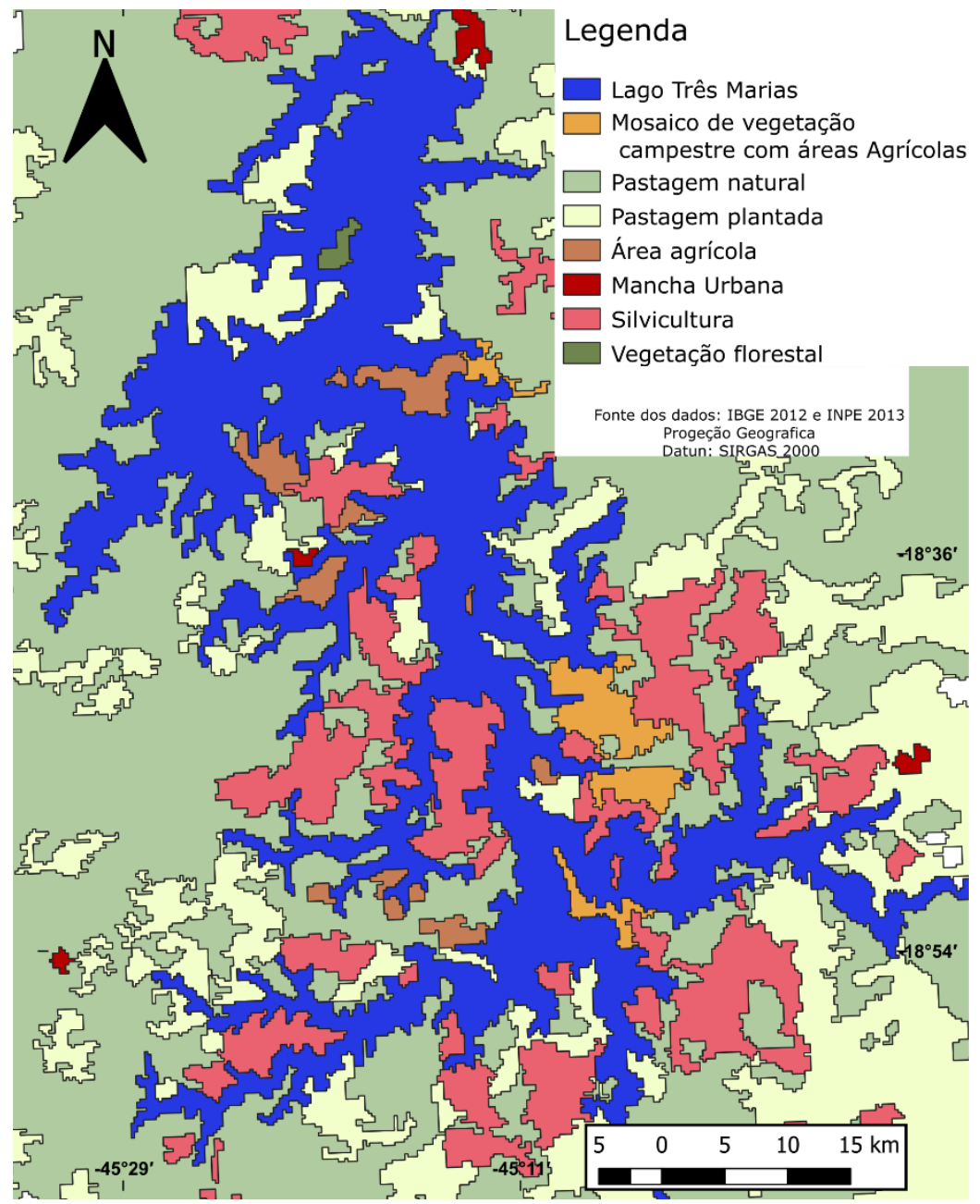

Figura 3

Mapa de uso e ocupação da terra.

\section{MATERIAIS E MÉTODOS}

O estudo foi realizado com amostras de água coletadas no lago represado da barragem de Três Marias. O trabalho de campo foi realizado entre os dias 19 e 21 de julho de 2018 em 58 pontos de coleta de águas superficiais, distribuídos ao longo do segmento fluvial, com pontos de coletas a cerca de $2 \mathrm{~km}$ uma da outra (Figura 4).
A escolha dos locais de coleta objetivava investigar possíveis contribuições de contaminantes químicos dos afluentes do Rio São Francisco para a barragem, além de verificar se tais contaminações são diluídas ou precipitadas na zona mista da barragem. Para isso, foram selecionados pontos adentrando as principais drenagens da barragem e pontos distribuídos ao longo do leito do rio represado 
(Figura 4). Além disso, foram planejados três perfis de margem na barragem, formando uma malha linear de amostragem de $500 \mathrm{em} 500 \mathrm{~m}$. Desta forma foi possível quantificar a contaminação do rio e entender a fonte poluidora.
Para as análises e preservação das amostras de água, foram obedecidas as metodologias descritas no Standard Methods for Examination of Water and Wastewater (RICE; AMERICAN PUBLIC HEALTH ASSOCIATION 2012).

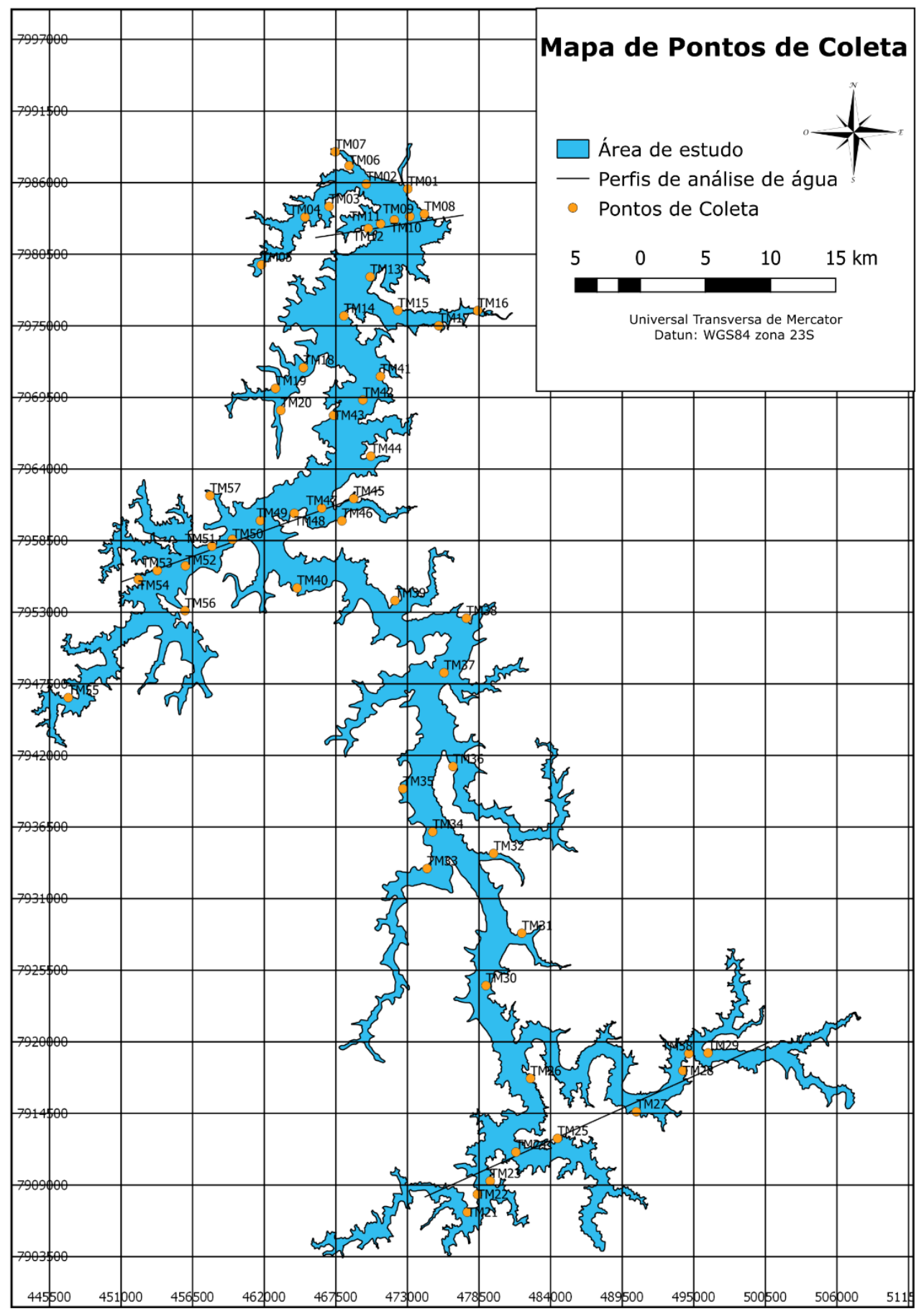

Figura 4 Mapa de pontos de coleta de água. 
Todos os pontos amostrados foram georreferenciados com GPS Garmin Oregon 550. As amostras foram coletadas a uma profundidade de 10 a $30 \mathrm{~cm}$ e acondicionadas em frascos de polietileno $(500 \mathrm{~mL})$, acondicionados em uma caixa de isopor e armazenados a uma temperatura de aproximadamente $2^{\circ} \mathrm{C}$ até sua chegada ao laboratório. Utilizou-se um barco a motor para a coleta de água na represa.

Os parâmetros físico-químicos não conservativos [temperatura $(\mathrm{T})$, potencial hidrogeniônico $(\mathrm{pH})$, turbidez, condutividade elétrica (CE), oxigênio dissolvido (OD), sólidos totais dissolvidos (STD), potencial óxido-redução (ORP)] foram determinados in situ através da sonda multiparâmetro HANNA, modelo HI 98190 e do portable Turbdimeter HANNA HI 98703. Parâmetros como cor aparente da água e espécies químicas (Al, B, $\mathrm{Fe}, \mathrm{Zn}, \mathrm{Mn}, \quad \mathrm{NH}_{3}, \quad \mathrm{NO}_{2}, \mathrm{NO}_{3}, \mathrm{SO}_{4}{ }^{{ }^{-}}$e tensoativos) foram obtidos no laboratório de Geoquímica Ambiental (LGA/UFVJM) usando um fotômetro multiparâmetro HI 83206 .

Os dados obtidos foram comparados aos valores referenciais da resolução CONAMA 357 de 2005 ou da Portaria do Ministério da Saúde MP 2914 de 2011. Estas Normas não estabelecem valores limites para ORP e CE. No entanto são importantes para avaliar a qualidade da água. Vale acentuar que a área de estudo se enquadra na categoria de recurso hídrico de classe 2 segundo o CONAMA $357 / 05$, pois a água da área de estudo é utilizada tanto para o abastecimento para consumo humano, quanto para a recreação de contato primário.

\section{RESULTADOS E DISCUSSÃO}

\subsection{PARÂMETROS FÍSICO-QUÍMICOS NÃO CONSERVATIVOS}

A tabela 1 mostra os resultados dos parâmetros físico-químicos não conservativos das análises das águas do rio. Os resultados destas análises mostraram que tais parâmetros mesurados estão em acordo com o que

\subsubsection{POTENCIAL HIDROGENIÔNICO (pH)}

Em termos de saúde pública, somente água extremamente ácida ou básica poderiam causar algum tipo de transtorno como irritação na pele ou nos olhos. Entretanto, em um ambiente aquático, quando os valores de $\mathrm{pH}$ se afastam da neutralidade, mesmo para valores pequenos, podem ocasionar condições que afetem a vida de peixes ou de microrganismos (VON SPERLING 2014a). A Resolução CONAMA

\subsubsection{OXIGÊNIO DISSOLVIDO (OD)}

Para o oxigênio dissolvido a Resolução CONAMA 357/05 demarca valores acima de 5 $\mathrm{mg} / \mathrm{L}$ de $\mathrm{O}_{2}$ para ambientes não impactados. $\mathrm{O}$ valor mínimo medido na área de estudo foi de $4,69 \mathrm{mg} / \mathrm{L}$ de $\mathrm{O}_{2}$. Entretanto a média das amostras é $6,89 \mathrm{mg} / \mathrm{L}$ de $\mathrm{O}_{2}$, mostrando que, apesar da maioria das amostras apresentaremse de acordo com as normas para OD, alguns pontos demostram condições ambientalmente preconiza as legislações ambientais vigentes. Entretanto é importante uma atenção para o pH e o oxigênio dissolvido que apresentam valores no limite do recomendado.

$357 / 05$ estabelece para o $\mathrm{pH}$ uma faixa limite ente 6 e 9.

Os resultados encontrados para o $\mathrm{pH}$ da água em estudo estão no limiar dos valores estabelecidos pelas normas governamentais, mostrando o potencial de suscetibilidade ambiental iminente para a área (Figura 5). Os valores mínimo e máximo medidos foram, respectivamente, 6,57 e 8,75 . A média dos valores é 7,62.

irregulares e quase todos no limite do recomendado (Figura 6).

Dentre os valores encontrados para OD, no ponto TM-55 o valor medido foi de $30,1 \mathrm{mg} / \mathrm{L}$ de $\mathrm{O}_{2}$ destoando dos demais. É provável que esse valor elevado seja devido à forte atividade dos ventos que produzem localmente ondas e perturbação da água. 
Tabela 1- Resultados das análises para os parâmetros físico-químico não conservativos.

\begin{tabular}{|c|c|c|c|c|c|c|c|c|}
\hline & $\begin{array}{c}\text { Temperatura } \\
\left({ }^{\circ} \mathrm{C}\right)\end{array}$ & pH & $\begin{array}{l}\text { ORP } \\
(\mathrm{mV})\end{array}$ & $\begin{array}{c}\mathrm{CE} \\
(\mu \mathrm{S} / \mathrm{cm})\end{array}$ & $\begin{array}{c}\mathrm{OD} \\
(\mathrm{mg} / \mathrm{L}) \\
\end{array}$ & $\begin{array}{c}\text { STD } \\
(\mathrm{mg} / \mathrm{L}) \\
\end{array}$ & $\begin{array}{c}\text { Turbidez } \\
\text { (UNT) }\end{array}$ & $\begin{array}{c}\text { Cor Aparente } \\
(\mathrm{Pt} / \mathrm{L})\end{array}$ \\
\hline Pontos $\backslash$ Limites & 40 & $6-9$ & & & 5,00 & 500 & 100 & 75 \\
\hline TM-01 & 22,85 & 7,69 & 230 & 74 & 6,96 & 48 & 2,32 & 9,16 \\
\hline TM-02 & 23,15 & 7,33 & 219 & 74 & 7,14 & 48 & 2,95 & 9,38 \\
\hline TM-03 & 22,93 & 7,58 & 174 & 73 & 7,20 & 48 & 3,87 & 5,23 \\
\hline TM-04 & 23,12 & 7,59 & 160 & 73 & 7,46 & 48 & 0,13 & 4,74 \\
\hline TM-05 & 22,60 & 7,33 & 109 & 75 & 4,69 & 49 & 4,03 & 18,51 \\
\hline TM-06 & 23,30 & 7,61 & 122 & 75 & 5,36 & 49 & 5,29 & 4,15 \\
\hline TM-07 & 23,49 & 7,25 & 142 & 73 & 5,76 & 48 & 3,67 & 13,70 \\
\hline TM-08 & 23,51 & 7,54 & 134 & 74 & 6,05 & 48 & 5,11 & 10,33 \\
\hline TM-09 & 23,51 & 6,57 & 229 & 78 & 7,70 & 48 & 4,32 & 8,03 \\
\hline TM-10 & 23,64 & 7,28 & 171 & 73 & 7,32 & 42 & 4,82 & 15,72 \\
\hline TM-11 & 23,84 & 6,90 & 189 & 74 & 7,58 & 48 & 3,86 & 11,66 \\
\hline TM-12 & 24,09 & 8,03 & 131 & 74 & 7,51 & 48 & 8,10 & 20,70 \\
\hline TM-13 & 23,91 & 6,67 & 197 & 74 & 7,89 & 48 & 0,08 & 12,26 \\
\hline TM-14 & 24,87 & 8,07 & 142 & 73 & 8,59 & 48 & 0,00 & 8,18 \\
\hline TM-15 & 24,09 & 6,99 & 204 & 73 & 6,34 & 47 & 4,39 & 22,79 \\
\hline TM-16 & 23,85 & 7,04 & 172 & 73 & 5,80 & 47 & 5,21 & 18,91 \\
\hline TM-17 & 23,94 & 7,46 & 150 & 74 & 6,06 & 48 & 5,57 & 12,47 \\
\hline TM-18 & 24,18 & 7,53 & 148 & 74 & 7,61 & 48 & 2,30 & 23,12 \\
\hline TM-19 & 24,19 & 8,19 & 132 & 75 & 6,54 & 49 & 7,52 & 23,32 \\
\hline TM-20 & 25,10 & 8,55 & 109 & 75 & 7,64 & 49 & 4,86 & 12,81 \\
\hline TM-21 & 22,26 & 7,71 & 162 & 74 & 6,28 & 48 & 3,46 & 27,22 \\
\hline TM-22 & 22,63 & 7,56 & 153 & 77 & 5,52 & 50 & 5,27 & 29,07 \\
\hline TM-23 & 22,85 & 7,59 & 147 & 75 & 6,01 & 49 & 2,57 & 19,30 \\
\hline TM-24 & 22,78 & 7,36 & 155 & 76 & 7,07 & 50 & 6,83 & 17,82 \\
\hline TM-25 & 22,80 & 7,56 & 143 & 77 & 5,30 & 50 & 11,14 & 58,64 \\
\hline TM-26 & 23,12 & 7,67 & 133 & 76 & 6,87 & 50 & 10,85 & 17,71 \\
\hline TM-27 & 23,39 & 7,68 & 130 & 84 & 5,91 & 55 & 5,86 & 29,93 \\
\hline TM-28 & 23,41 & 7,73 & 122 & 85 & 5,25 & 55 & 4,59 & 19,22 \\
\hline TM-29 & 23,26 & 7,54 & 130 & 84 & 5,50 & 55 & 4,42 & 18,18 \\
\hline TM-30 & 23,75 & 7,24 & 162 & 76 & 7,55 & 49 & 2,58 & 12,41 \\
\hline TM-31 & 23,64 & 7,71 & 141 & 76 & 6,18 & 49 & 2,87 & 18,54 \\
\hline TM-32 & 24,63 & 7,86 & 129 & 75 & 7,13 & 48 & 8,26 & 40,50 \\
\hline TM-33 & 23,97 & 7,68 & 133 & 75 & 5,51 & 48 & 4,45 & 26,79 \\
\hline TM-34 & 24,39 & 7,66 & 128 & 74 & 7,04 & 48 & 2,59 & 10,69 \\
\hline TM-35 & 25,38 & 7,69 & 133 & 75 & 6,63 & 48 & 3,17 & 19,45 \\
\hline TM-36 & 25,52 & 8,08 & 122 & 73 & 6,65 & 48 & 3,62 & 19,79 \\
\hline TM-37 & 24,70 & 7,40 & 151 & 74 & 7,00 & 48 & 1,93 & 12,47 \\
\hline TM-38 & 24,99 & 7,87 & 127 & 74 & 7,59 & 48 & 19,91 & 61,42 \\
\hline TM-39 & 25,04 & 8,75 & 94 & 74 & 6,46 & 48 & 4,33 & 24,58 \\
\hline TM-40 & 24,85 & 7,86 & 131 & 73 & 6,05 & 48 & 4,64 & 21,92 \\
\hline TM-41 & 23,30 & 7,93 & 154 & 73 & 6,41 & 48 & 2,58 & 10,14 \\
\hline TM-42 & 23,27 & 7,80 & 146 & 74 & 5,50 & 48 & 1,43 & 4,64 \\
\hline TM-43 & 24,00 & 7,59 & 151 & 73 & 5,42 & 48 & 2,86 & 18,57 \\
\hline TM-44 & 23,42 & 7,82 & 21 & 73 & 6,44 & 47 & 6,05 & 17,11 \\
\hline TM-45 & 23,42 & 7,67 & 86 & 74 & 5,37 & 48 & 3,67 & 13,37 \\
\hline TM-46 & 23,72 & 8,27 & 34 & 76 & 6,10 & 49 & 2,85 & 21,34 \\
\hline TM-47 & 23,62 & 7,63 & 91 & 74 & 6,75 & 48 & 2,32 & 9,83 \\
\hline TM-48 & 23,89 & 7,74 & 95 & 73 & 5,54 & 48 & 6,38 & 17,13 \\
\hline TM-49 & 23,69 & 7,30 & 128 & 74 & 6,65 & 48 & 4,67 & 10,79 \\
\hline TM-50 & 23,61 & 6,96 & 155 & 73 & 6,10 & 48 & 3,71 & 14,62 \\
\hline TM-51 & 25,00 & 8,37 & 86 & 72 & 7,22 & 47 & 5,94 & 15,82 \\
\hline TM-52 & 23,66 & 7,78 & 113 & 73 & 6,53 & 47 & 1,98 & 11,62 \\
\hline TM-53 & 23,64 & 6,78 & 174 & 73 & 6,67 & 48 & 2,30 & 11,85 \\
\hline TM-54 & 24,73 & 7,83 & 112 & 73 & 5,31 & 47 & 30,68 & 174,72 \\
\hline TM-55 & 23,38 & 7,45 & 149 & 73 & 30,1 & 47 & 4,46 & 40,76 \\
\hline TM-56 & 25,22 & 7,72 & 125 & 72 & 5,90 & 47 & 3,19 & 23,34 \\
\hline TM-57 & 25,28 & 7,86 & 122 & 72 & 5,74 & 47 & 3,60 & 39,49 \\
\hline TM-58 & 23,30 & 7,70 & 127 & 85 & 5,80 & 55 & 4,97 & 26,45 \\
\hline
\end{tabular}




\subsubsection{TEMPERATURA}

A resolução CONAMA 430/11 alterou a norma para a temperatura, de forma que o limite de $40^{\circ} \mathrm{C}$ estabelecido anteriormente a 2011, atualmente só é exigido como valor máximo para temperatura de efluentes. Para além do limite de temperatura, a resolução CONAMA 430/11 não permite que efluentes alterem a temperatura da zona mistura acima de $3{ }^{\circ} \mathrm{C}$.

\subsubsection{SÓLIDOS TOTAIS DISSOLVIDOS (STD)}

Os STD medidos na área de estudo estão muito abaixo dos valores estabelecidos pelas normas governamentais (Resolução CONAMA 375/05), que definem como ambientes impactados aqueles com concentrações acima de $500 \mathrm{mg} / \mathrm{L}$ (Figura 8). Neste estudo o valor máximo encontrado foi de $55 \mathrm{mg} / \mathrm{L}$ e o mínimo de $42 \mathrm{mg} / \mathrm{L}$. A média dos valores observados é de $48,38 \mathrm{mg} / \mathrm{L}$, o que mostra que

\subsubsection{TURBIDEZ}

A Resolução CONAMA 357/05 estabelece valores limites para turbidez de 100 Unidades Nefelométricas de Turbidez (UNT). Comparando os valores obtidos com os valores de referência, nenhum ponto violou o limite estabelecido (Figura 10), sendo que dois pontos (TM-38 com 19,91 UNT e TM-54 com 30,68 UNT) apresentaram valores

\subsubsection{COR APARENTE}

As amostras analisadas não apresentaram cor aparente acima do que estabelece a legislação (Figura 10), com exceção do ponto TM-54. A média das amostras analisadas é de $21,88 \mathrm{Pt} / \mathrm{L}$, dentre os analisados o valor máximo é de $174,72 \mathrm{Pt} / \mathrm{L}$ para o ponto

\subsubsection{CONDUTIVIDADE ELÉTRICA (CE)}

A legislação brasileira não apresenta limites para esse parâmetro, de modo que a oscilação da CE não gera diretamente impacto à qualidade da água. Entretanto a análise de concentração iônica das águas mostra que valores muito altos de $\mathrm{CE}$ são indício de contaminação do meio aquático. Em geral níveis acima de $100 \mu \mathrm{S} / \mathrm{cm}$, a $25^{\circ} \mathrm{C}$, indicam ambientes impactados (CETESB, 2017). Os valores mensurados no campo para esse parâmetro mostram-se próximos a $100 \mu \mathrm{S} / \mathrm{cm}$, sendo o valor para a média de todos os pontos
Os dados medidos na área mostraram que a temperatura da água do lago tem um comportamento muito homogêneo (Figura 7), com sutis oscilações no período mais quente do dia (entre $12 \mathrm{~h}$ e $15 \mathrm{~h}$ ). O valor máximo medido, às $15: 10 \mathrm{~h}$, foi de $25,52{ }^{\circ} \mathrm{C}$. $\mathrm{O}$ valor mínimo foi de $22,26{ }^{\circ} \mathrm{C}$ medido as $08: 40 \mathrm{~h}$. A média das medidas é de $23,83^{\circ} \mathrm{C}$.

para este parâmetro a água da barragem não apresenta problemas de contaminação. Todavia, para outros parâmetros apresentados nesse trabalho há constatação de contaminação. Isso porque, apesar de um elemento apresentar concentrações altas, o somatório de todos os elementos não necessariamente se apresentará acima do limite permitido pela referência

significativamente maiores que a média de todos os pontos $(4,92$ UNT). Os valores maiores nesses locais são devido à forte presença natural de material siliciclásticos argiloso em suspenção, contribuição dos pelitos do Grupo Bambuí, como mostra a Figura 9.

anteriormente citado e o valor mínimo é de $4,15 \mathrm{Pt} / \mathrm{L}$ para o ponto TM-06. O valor estabelecido pela resolução CONAMA 357/05 é de $75 \mathrm{Pt} / \mathrm{L}$. De forma semelhante à turbidez, o material argiloso na margem do rio contribui com o aumento da cor aparente.

de 74,61 $\mu \mathrm{S} / \mathrm{cm}$, indicando que a área ou apresenta contaminação, ou está na iminência da suscetibilidade ambiental. $\mathrm{O}$ valor mais alto para CE é de $85 \mu \mathrm{S} / \mathrm{cm}$ e o mais baixo é de 72 $\mu \mathrm{S} / \mathrm{cm}$.

Os quatro maiores valores medidos (Tabela 1) são dos pontos TM-27, TM-28, TM-29 e TM-58, todos localizados na entrada do Rio Paraopeba, indicando que o rio pode ser um contribuinte de contaminante para o logo represado. 


\subsubsection{POTENCIAL DE OXIDAÇÃO E REDUÇÃO (ORP)}

O mesmo valor de ORP pode caracterizar diferentes composições ou reações químicas presentes na água, desta forma o ORP não ser utilizado como um parâmetro de avaliação direta da qualidade da água. Contudo, o ORP pode ser um parâmetro comparativo entre ambientes diferentes, portanto serve como um indicio de mudança de característica de um corpo d'água para outro (GONCHARUK et al. 2010). Quanto às normas governamentais, também não existe um valor limite para delimitar a qualidade da água de acordo com o ORP. Observa-se relevante diferença entre os valores obtidos, sendo o maior valor para ORP de $230 \mathrm{mV}$ e o menor de $21 \mathrm{mV}$. A média de todos os valores é de 139,16 mV, (Figura 11).

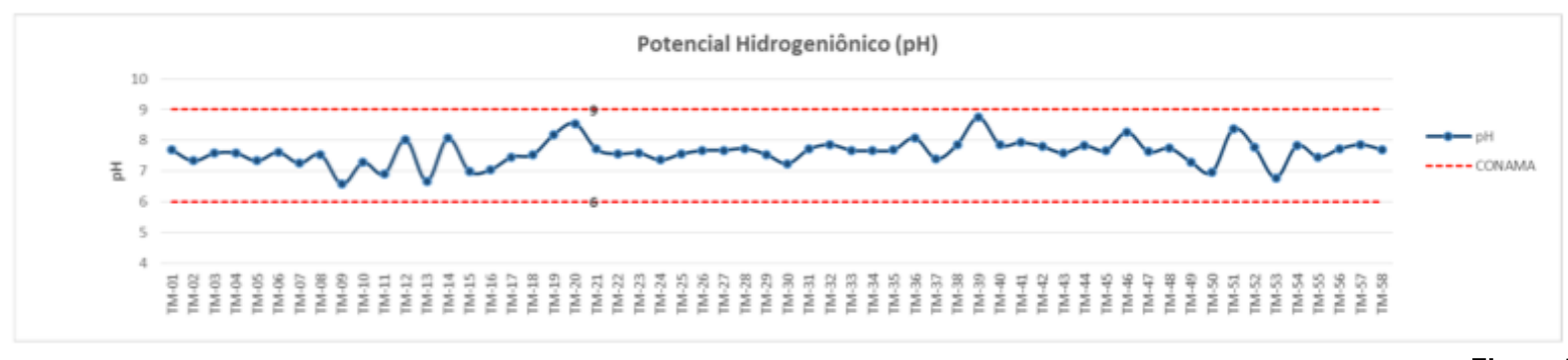

Figura 5

Gráfico com os valores medidos para pH - em vermelho destaca-se o limite estabelecido pela Resolução CONAMA 357/05.

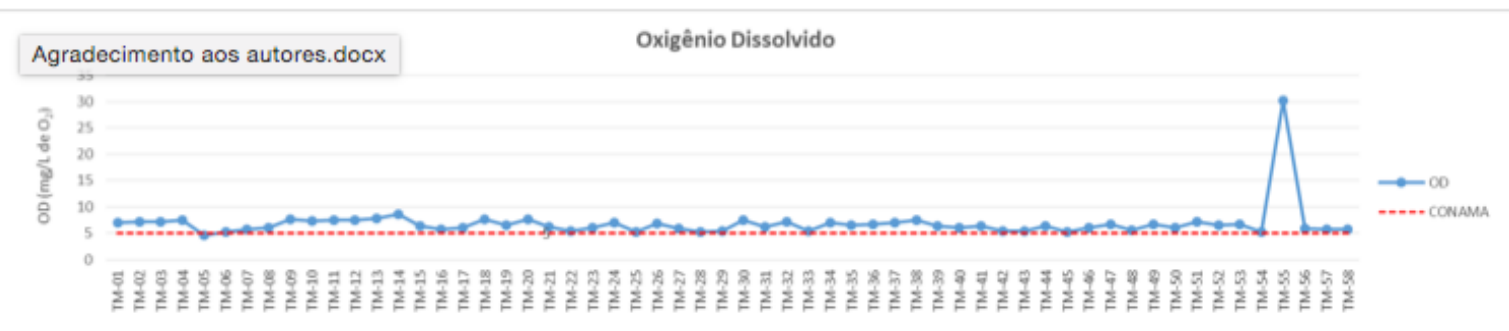

Figura 6

Gráfico com os valores medidos para OD - em vermelho destaca-se o limite estabelecido pela Resolução CONAMA 357/05.

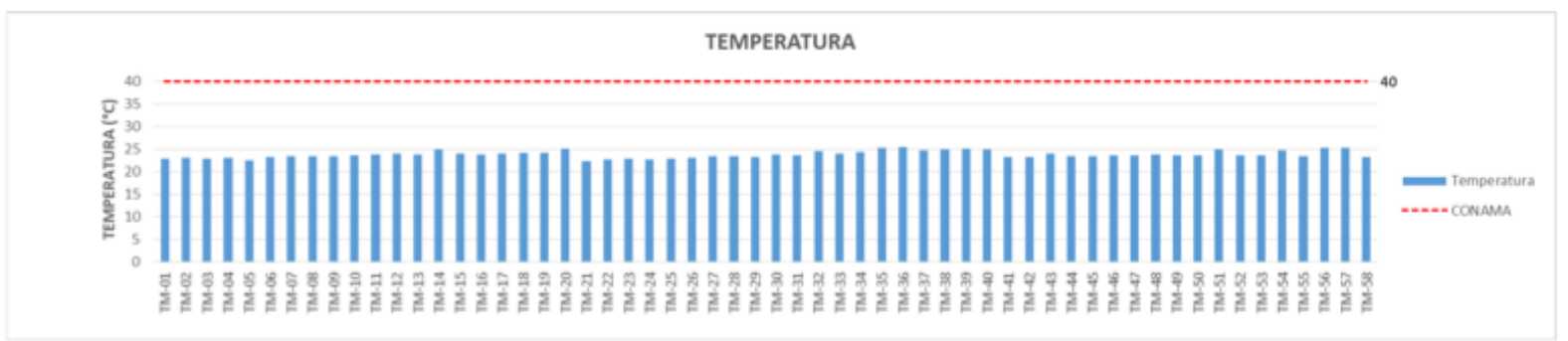

Figura 7

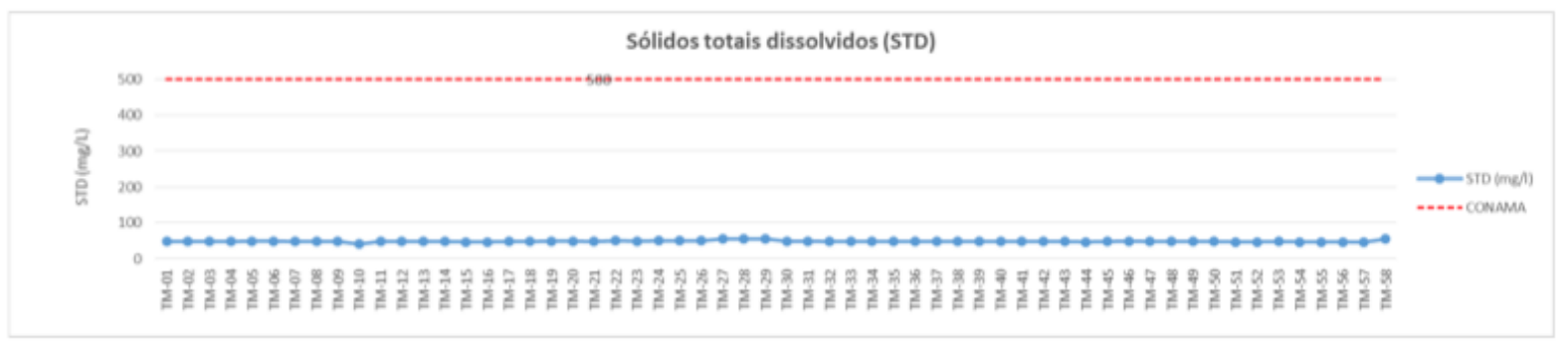

Figura 8

Gráfico com os valores medidos para STD - em vermelho destaca-se o limite estabelecido pela resolução CONAMA 357/05 

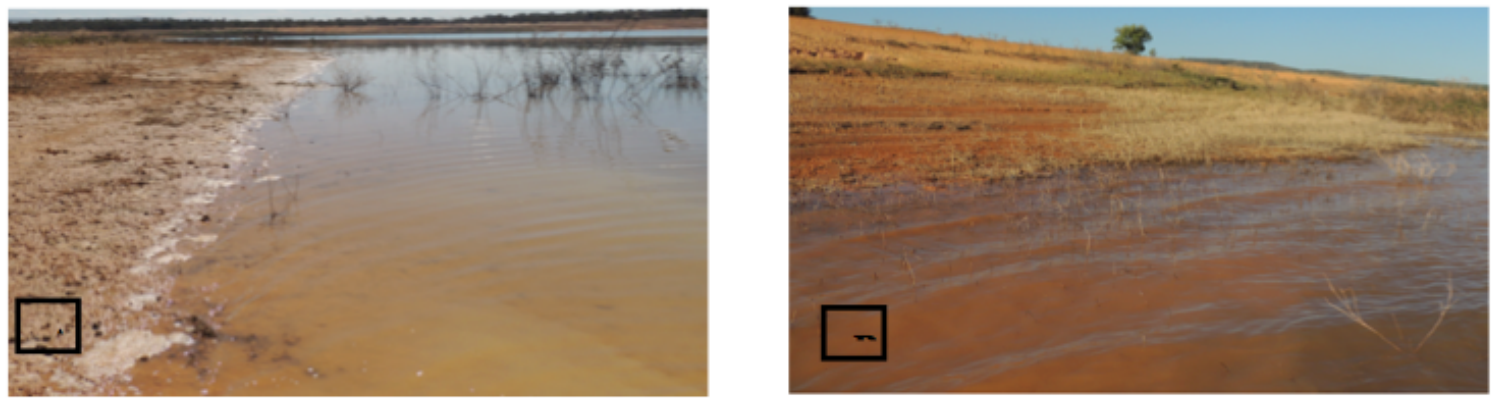

Figura 9 Imagens dos pontos TM-54 (A) e TM- 38 (B). Água com aspecto turvo devido ao material argiloso em suspenção

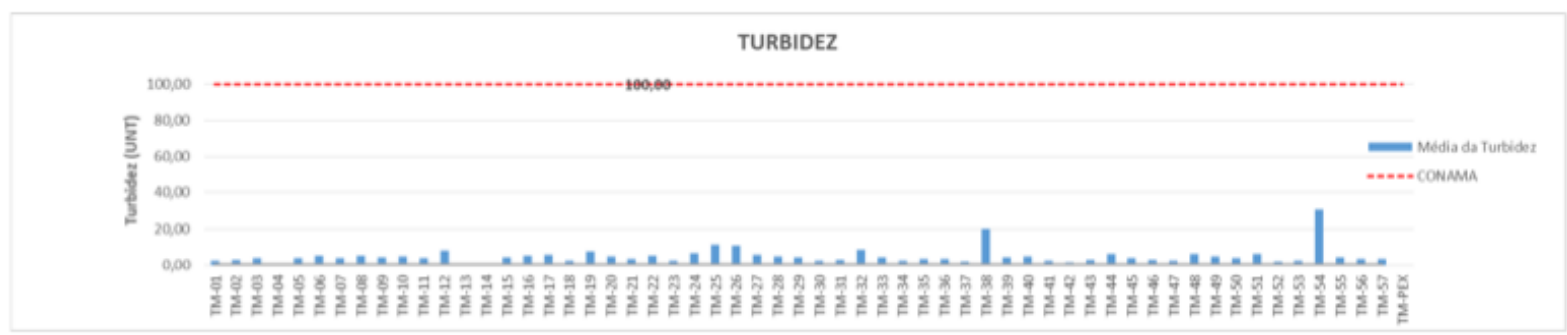

Figura 10

Gráfico com os valores medidos para Turbidez - em vermelho destaca-se o limite estabelecido pela resolução CONAMA 357/05

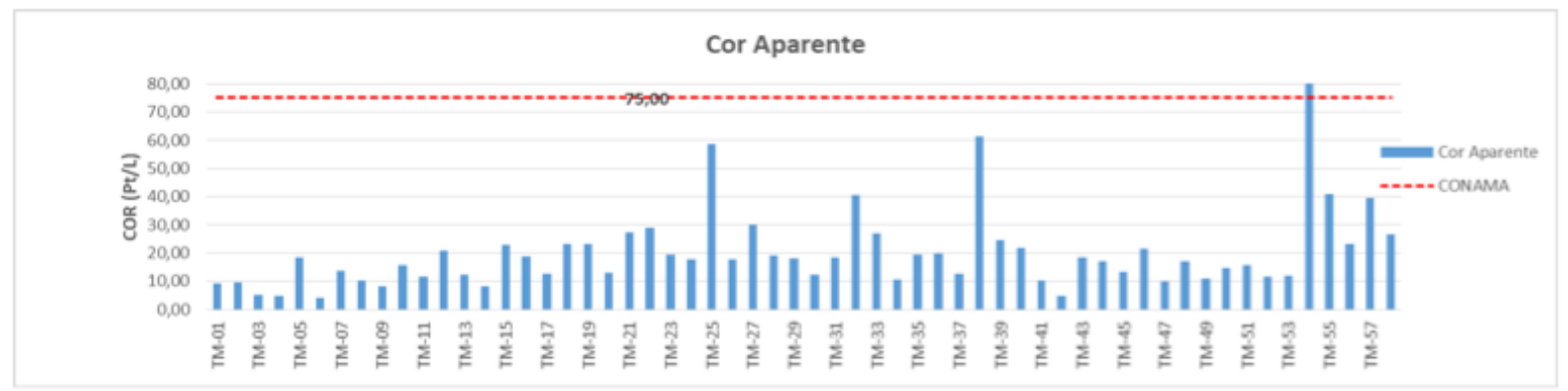

Figura 11

Gráfico com os valores medidos para cor aparente - em vermelho destaca-se o limite estabelecido pela resolução CONAMA 357/05

ORP

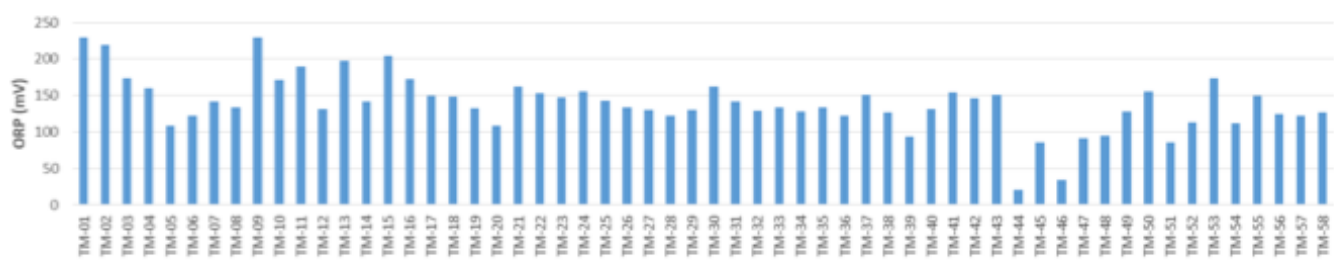

Figura 12 Gráfico com os valores medidos para ORP.

\subsection{PARÂMETROS DE QUÍMICA TOTAL}

Neste trabalho utilizou um fotômetro para analisar a concentração, dissolvida e em suspenção, das seguintes substâncias na água estudada: Detergente; sulfato; amônia; nitrito; nitrato; alumínio; fosfato total; zinco; ferro; boro; manganês. A tabela 2 mostra os resultados obtidos. Vale ressaltar que a amostra TM-03 não tem dados dos parâmetros químicos devido a um problema de perda de amostra no transporte. 
Tabela 2 - Resultados das análises para os parâmetros de química total. Todas as concentrações estão em mg/L.

\begin{tabular}{|c|c|c|c|c|c|c|c|c|c|c|}
\hline & LAS $*$ & $\mathrm{SO}_{4}$ & $\mathbf{N H}_{\mathbf{3}}$ & $\mathbf{N O}_{2}$ & $\mathbf{N O}_{3}$ & Al & $\mathbf{Z n}$ & $\mathbf{F e}$ & Mn & $\mathbf{B}$ \\
\hline Limites & 0,5 & 250 & 0,5 & 1,0 & 10 & 0,1 & 0,18 & 0,3 & 0,1 & 0,5 \\
\hline TM-01 & 0,29 & 1,28 & 0,22 & 0,00 & 1,10 & 0,14 & 0,04 & 0,02 & 0,14 & 0 \\
\hline TM-02 & 0,49 & 3,00 & 0,23 & 0,01 & 0,49 & 0,14 & 0,04 & 0,04 & 0,07 & 0,01 \\
\hline TM-04 & 0,68 & 0,96 & 0,15 & 0,02 & 1,03 & 0,14 & 0,04 & 0,04 & 0,04 & 0 \\
\hline TM-05 & 0,36 & 1,92 & 0,36 & 0,01 & 2,45 & 0,16 & 0,04 & 0,08 & 0,07 & 0 \\
\hline TM-06 & 0,18 & 5,42 & 0,27 & 0,01 & 4,08 & 0,15 & 0,05 & 0,01 & 0,04 & 0 \\
\hline TM-07 & 0,32 & 4,35 & 0,28 & 0,01 & 3,15 & 0,15 & 0,04 & 0,09 & 0,07 & 0,02 \\
\hline TM-08 & 0,39 & 3,96 & 0,30 & 0,01 & 4,91 & 0,11 & 0,03 & 0,03 & 0,11 & 0,08 \\
\hline TM-09 & 0,38 & 3,83 & 0,21 & 0,01 & 2,57 & 0,12 & 0,03 & 0,02 & 0,07 & 0,41 \\
\hline TM-10 & 0,09 & 6,05 & 0,17 & 0,01 & 3,23 & 0,14 & 0,03 & 0,04 & 0,07 & 0,9 \\
\hline TM-11 & 0,05 & 3,82 & 0,25 & 0,01 & 1,83 & 0,12 & 0,03 & 0,02 & 0,06 & 0 \\
\hline TM-12 & 0,40 & 2,07 & 0,27 & 0,01 & 2,91 & 0,14 & 0,03 & 0,04 & 0,06 & 0,62 \\
\hline TM-13 & 0,36 & 2,50 & 0,14 & 0,02 & 2,88 & 0,11 & 0,03 & 0,02 & 0,09 & 0 \\
\hline TM-14 & 0,26 & 1,58 & 0,17 & 0,01 & 2,75 & 0,12 & 0,04 & 0,03 & 0,09 & 0 \\
\hline TM-15 & 0,17 & 0,62 & 0,23 & 0,00 & 2,21 & 0,13 & 0,03 & 0,01 & 0,10 & 0,01 \\
\hline TM-16 & 0,27 & 3,75 & 0,20 & 0,01 & 2,25 & 0,12 & 0,03 & 0,02 & 0,07 & 0 \\
\hline TM-17 & 0,48 & 0,84 & 0,26 & 0,00 & 3,33 & 0,11 & 0,03 & 0,01 & 0,10 & 0,05 \\
\hline TM-18 & 0,34 & 0,78 & 0,32 & 0,01 & 4,34 & 0,12 & 0,03 & 0,02 & 0,06 & 0,14 \\
\hline TM-19 & 0,51 & 1,60 & 0,26 & 0,01 & 3,51 & 0,12 & 0,03 & 0,03 & 0,09 & 0,01 \\
\hline TM-20 & 0,29 & 3,24 & 0,13 & 0,01 & 2,27 & 0,15 & 0,04 & 0,04 & 0,07 & 0 \\
\hline TM-21 & 0,17 & 0,45 & 0,10 & 0,02 & 3,54 & 0,14 & 0,04 & 0,05 & 0,08 & 0 \\
\hline TM-22 & 0,21 & 3,99 & 0,09 & 0,02 & 3,82 & 0,14 & 0,04 & 0,05 & 0,11 & 0 \\
\hline TM-23 & 0,12 & 2,15 & 0,08 & 0,01 & 3,98 & 0,15 & 0,04 & 0,06 & 0,05 & 0 \\
\hline TM-24 & 0,16 & 2,30 & 0,08 & 0,01 & 3,88 & 0,17 & 0,04 & 0,04 & 0,08 & 0 \\
\hline TM-25 & 0,12 & 3,95 & 0,10 & 0,02 & 4,51 & 0,14 & 0,05 & 0,10 & 0,09 & 0 \\
\hline TM-26 & 0,21 & 9,11 & 0,25 & 0,01 & 3,32 & 0,10 & 0,04 & 0,07 & 0,06 & 0,01 \\
\hline TM-27 & 0,54 & 9,44 & 0,18 & 0,02 & 3,23 & 0,11 & 0,04 & 0,01 & 0,06 & 0 \\
\hline TM-28 & 0,24 & 6,16 & 0,29 & 0,02 & 3,00 & 0,13 & 0,04 & 0,02 & 0,06 & 0 \\
\hline TM-29 & 0,24 & 2,43 & 0,16 & 0,01 & 2,58 & 0,11 & 0,04 & 0,04 & 0,06 & 0 \\
\hline TM-30 & 0,36 & 4,35 & 0,26 & 0,02 & 4,62 & 0,15 & 0,05 & 0,03 & 0,08 & 0 \\
\hline TM-31 & 0,22 & 7,68 & 0,18 & 0,01 & 4,43 & 0,12 & 0,05 & 0,04 & 0,06 & 0 \\
\hline TM-32 & 0,20 & 3,48 & 0,22 & 0,01 & 4,41 & 0,13 & 0,05 & 0,06 & 0,06 & 0,05 \\
\hline TM-33 & 0,31 & 1,07 & 0,19 & 0,02 & 3,81 & 0,12 & 0,04 & 0,04 & 0,05 & 0,03 \\
\hline TM-34 & 0,34 & 4,29 & 0,10 & 0,01 & 3,28 & 0,12 & 0,05 & 0,03 & 0,07 & 0,01 \\
\hline TM-35 & 0,22 & 2,33 & 0,19 & 0,01 & 3,96 & 0,12 & 0,04 & 0,04 & 0,02 & 0,15 \\
\hline TM-36 & 0,12 & 1,95 & 0,28 & 0,01 & 1,79 & 0,10 & 0,03 & 0,04 & 0,08 & 0 \\
\hline TM-37 & 0,37 & 0,90 & 0,21 & 0,01 & 0,65 & 0,11 & 0,04 & 0,06 & 0,06 & 0,01 \\
\hline TM-38 & 0,17 & 10,16 & 0,39 & 0,01 & 2,14 & 0,15 & 0,04 & 0,06 & 0,04 & 0,01 \\
\hline TM-39 & 0,25 & 4,41 & 0,25 & 0,02 & 2,72 & 0,14 & 0,04 & 0,05 & 0,04 & 0,64 \\
\hline TM-40 & 0,23 & 4,86 & 0,26 & 0,00 & 1,89 & 0,15 & 0,04 & 0,07 & 0,06 & 0,08 \\
\hline TM-41 & 0,19 & 8,24 & 0,26 & 0,00 & 1,12 & 0,13 & 0,04 & 0,03 & 0,07 & 0,01 \\
\hline TM-42 & 0,19 & 6,55 & 0,24 & 0,01 & 3,16 & 0,13 & 0,04 & 0,05 & 0,05 & 0 \\
\hline TM-43 & 0,24 & 5,56 & 0,20 & 0,01 & 1,96 & 0,15 & 0,05 & 0,03 & 0,07 & 0,02 \\
\hline TM-44 & 0,11 & 4,25 & 0,24 & 0,01 & 2,16 & 0,10 & 0,04 & 0,06 & 0,08 & 0 \\
\hline TM-45 & 0,27 & 8,66 & 0,13 & 0,01 & 3,49 & 0,11 & 0,04 & 0,04 & 0,10 & 0,01 \\
\hline TM-46 & 0,18 & 1,18 & 0,15 & 0,02 & 3,08 & 0,10 & 0,05 & 0,04 & 0,05 & 0 \\
\hline TM-47 & 0,28 & 6,59 & 0,13 & 0,01 & 2,32 & 0,13 & 0,04 & 0,02 & 0,09 & 0 \\
\hline TM-48 & 0,11 & 3,02 & 0,13 & 0,02 & 1,90 & 0,10 & 0,04 & 0,01 & 0,11 & 0 \\
\hline TM-49 & 0,21 & 3,06 & 0,20 & 0,01 & 2,43 & 0,11 & 0,04 & 0,02 & 0,09 & 0,05 \\
\hline TM-50 & 0,36 & 7,61 & 0,26 & 0,01 & 2,11 & 0,13 & 0,05 & 0,02 & 0,10 & 0,01 \\
\hline TM-51 & 0,18 & 2,83 & 0,23 & 0,01 & 2,18 & 0,14 & 0,05 & 0,02 & 0,09 & 0,01 \\
\hline TM-52 & 0,15 & 4,22 & 0,14 & 0,01 & 1,24 & 0,14 & 0,04 & 0,06 & 0,06 & 0 \\
\hline TM-53 & 0,37 & 1,70 & 0,19 & 0,01 & 2,40 & 0,14 & 0,05 & 0,04 & 0,11 & 0,3 \\
\hline TM-54 & 0,25 & 12,29 & 0,30 & 0,03 & 2,12 & 0,17 & 0,05 & 0,06 & 0,13 & 0 \\
\hline TM-55 & 0,21 & 4,72 & 0,26 & 0,01 & 1,28 & 0,14 & 0,05 & 0,02 & 0,12 & 0,54 \\
\hline TM-56 & 0,18 & 5,98 & 0,21 & 0,01 & 1,99 & 0,12 & 0,04 & 0,05 & 0,12 & 0,03 \\
\hline TM-57 & 0,22 & 5,47 & 0,06 & 0,01 & 0,15 & 0,12 & 0,04 & 0,04 & 0,08 & 0,01 \\
\hline TM-58 & 0,29 & 5,44 & 0,34 & 0,01 & 0,47 & 0,11 & 0,04 & 0,03 & 0,08 & 0,08 \\
\hline
\end{tabular}

* LAS - Detergente -sulfonato de alquil-benzeno de cadeia linear 


\subsubsection{SULFATO}

$\mathrm{Na}$ área de estudo, as concentrações de sulfato medidas mostram que a água analisada não tem problemas quanto a esse parâmetro. $\mathrm{O}$ menor valor medido foi de $4,11 \mathrm{mg} / \mathrm{L}$, enquanto que o maior valor medido foi de

\subsubsection{DETERGENTE}

A resolução CONAMA 357/05 utiliza a concentração do tensoativo sulfonato de alquilbenzeno de cadeia linear (LAS) como análise padrão. Assim sendo o limite aceitável para concentrações de detergentes em água é de 0,5 $\mathrm{mg} / \mathrm{L}$ de LAS. As amostras estudadas apresentaram valores altos para detergente sendo que em três pontos ultrapassaram o
$12,29 \mathrm{mg} / \mathrm{L}$. O limite tolerado pela resolução CONAMA 357/05 é de $250 \mathrm{mg} / \mathrm{L}$ de $\mathrm{SO}_{4}{ }^{-2}$ (Figura 13), de modo que as concentrações encontradas estão muito abaixo do limite preconizado pela legislação.

\subsubsection{COMPOSTOS À BASE DE NITROGÊNIO [AMÔNIA $\left(\mathrm{NH}_{3}\right), \operatorname{NITRITO}\left(\mathrm{NO}_{2}\right), \operatorname{NITRATO}\left(\mathrm{NO}_{3}\right)$ ]}

As normas estabelecidas pela Resolução CONAMA 357/05 apontam os valores limites de $1 \mathrm{mg} / \mathrm{L}$ de nitrito e $10 \mathrm{mg} / \mathrm{L}$ de nitrato. Para a amônia o valor aceitável, ainda segundo a legislação, depende do $\mathrm{pH}$ do ambiente analisado, de modo que, para $\mathrm{pH}$ menores que 7,5 o limite é de $3,7 \mathrm{mg} / \mathrm{L}$ de $\mathrm{NH}_{3}$; para $\mathrm{pH}$ entre 7,5 e 8,0 o limite é de $2 \mathrm{mg} / \mathrm{L}$ de $\mathrm{NH}_{3}$; para $\mathrm{pH}$ de 8,0 a 8,5 o limite é de $1 \mathrm{mg} / \mathrm{L}$ de $\mathrm{NH}_{3}$; para $\mathrm{pH}$ acima de 8,5 o limite é de 0,5 $\mathrm{mg} / \mathrm{L}$ de $\mathrm{NH}_{3}$. Nenhuma amostra apresentou concentração acima do limite de referência (Figura 15). Os valores máximos encontrados para amônia, nitrito e nitrato foram, respectivamente, $0,31 \mathrm{mg} / \mathrm{L}$ de $\mathrm{NH}_{3}, 0,03$ limite estabelecido pela legislação: TM-04 com concentração de $0,68 \mathrm{mg} / \mathrm{L}$ de LAS; TM19 com concentração de $0,51 \mathrm{mg} / \mathrm{L}$ de LAS e TM-27 com concentração de $0,54 \mathrm{mg} / \mathrm{L}$ de LAS (Figura 14). O valor mínimo de concentração para esse parâmetro foi de 0,05 $\mathrm{mg} / \mathrm{L}$ de LAS no ponto TM-11 e a média de todos os pontos foi de $0,26 \mathrm{mg} / \mathrm{L}$ de LAS.

\subsubsection{METAIS TOTAIS (ALUMÍNIO, ZINCO, FERRO, BORO E MANGANÊS)}

A Resolução CONAMA 357/05 considera os limites aceitáveis para a concentração de alumínio, zinco ferro, boro e manganês, respectivamente, $0,1 \mathrm{mg} / \mathrm{L} ; 0,18 \mathrm{mg} / \mathrm{L} ; 0,3$ $\mathrm{mg} / \mathrm{L} ; \quad 0,5 \mathrm{mg} / \mathrm{L} ; \quad 0,1 \mathrm{mg} / \mathrm{L}$. Dos metais analisados, o alumínio, o manganês e o boro apresentaram, em alguns pontos, valores acima do estabelecido pelas normas governamentais, enquanto que, nenhum dos pontos apresentou valores de concentração de ferro ou de zinco acima do limite recomendado (Figura 16).

Nota-se que quase todos os pontos de coleta, exceto o TM-26 e TM36, apresentaram concentrações de alumínio acima do recomendado, sendo o maior valor $0,17 \mathrm{mg} / \mathrm{L}$ de $\mathrm{Al}$ e o menor valor de $0,10 \mathrm{mg} / \mathrm{L}$ de $\mathrm{Al}$. A média de todos os valores mesurados para concentração de alumínio é de $0,13 \mathrm{mg} / \mathrm{L}$ de Al. $\mathrm{mg} / \mathrm{L}$ de $\mathrm{NO}_{2}$ e $4,91 \mathrm{mg} / \mathrm{L}$ de $\mathrm{NO}_{3}$. Ao passo que os menores valores foram, respectivamente, $0,03 \mathrm{mg} / \mathrm{L}$ de $\mathrm{NH}_{3}, 0,01$ $\mathrm{mg} / \mathrm{L}$ de $\mathrm{NO}_{2}$ e $0,15 \mathrm{mg} / \mathrm{L}$ de $\mathrm{NO}_{3}$. Os baixos valores de substâncias composta por nitrogênio destacam-se positivamente em toda área. Tais valores provavelmente são devidos à ausência de efluente sanitário de grande porte lançados diretamente no lago (PARRON et al. 2011). Entretanto, observa-se influências pontuais de efluentes devido à presença de altas concentrações de detergentes. Tal contribuição antrópica é significativa no Córrego Cachoeirinha (ponto TM-04).
Para o boro, 4 pontos de amostragem apresentaram-se acima do limite de contaminação (TM-10; TM-12; TM-39; TM55), sendo o valor máximo de $0,9 \mathrm{mg} / \mathrm{L}$ de $\mathrm{B}$. Entretanto a média dos valores, $0,08 \mathrm{mg} / \mathrm{L}$, medidos ficou muito aquém do valor de referência, sugerindo que a contaminação é pontual e se dilui no resto do lago.

Para o manganês, os valores encontrados, em geral, ou superam o limite máximo governamental ou ficam próximos de superar este limite. Em destaque o ponto TM-01 com o maior valor encontrado de $0,14 \mathrm{mg} / \mathrm{L}$. A média dos valores observados é de $0,08 \mathrm{mg} / \mathrm{L}$ de $\mathrm{Mn}$.

Dentre os elementos metálicos totais, o alumínio se destaca por apresentar altas concentrações em todos os pontos amostrados. Não obstante, esse resultado era esperado, pois o substrato rochoso da região conta fortemente 
com a presença de rochas arcosianas da Formação Três Marias. Portanto, provavelmente o alumínio registrado na área de estudo é decorrente da lixiviação dos feldspatos presente no solo ou na rocha da região. Análise semelhante pode ser levantada para o manganês, acreditando-se ser de origem natural.
O boro desempenha um importante papel no metabolismo dos organismos principalmente para as plantas, às vezes, presente em fertilizantes, corretivo de solo ou em ração para animais (BAGGIO, 2008). Como a região apresenta uma intensa atividade de piscicultura, é possível que a origem da contaminação de boro seja desta atividade econômica.

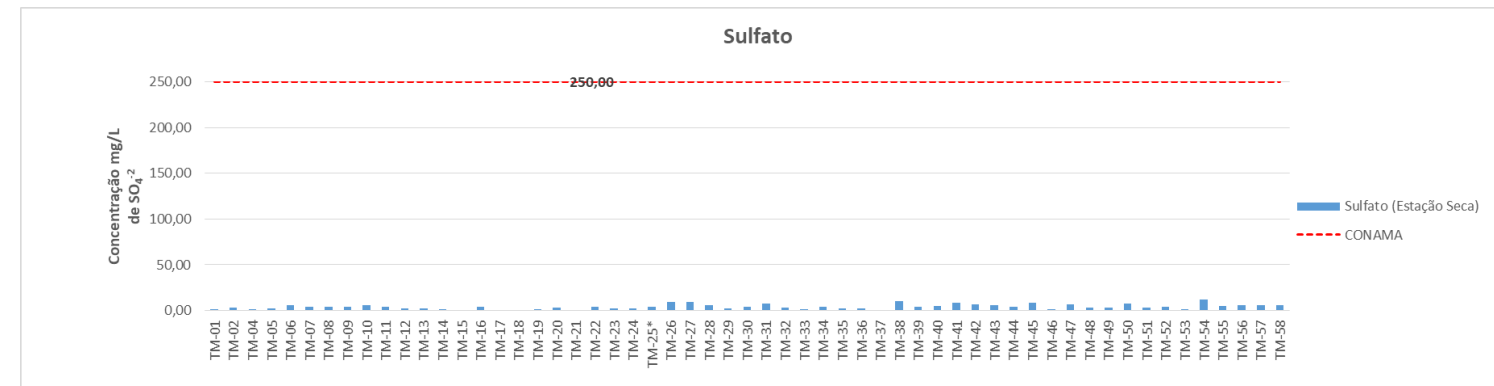

Figura 13

Gráfico com os valores medidos para Sulfato - em vermelho destaca-se o limite estabelecido pela resolução CONAMA 357/05

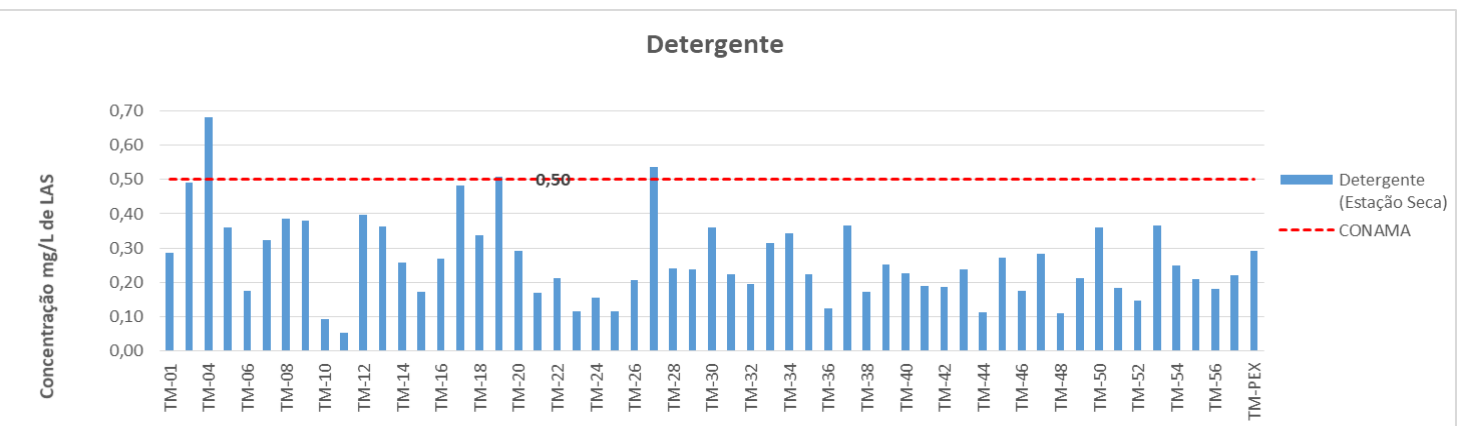

Figura 14

Gráfico com os valores medidos para detergente - em vermelho destaca-se o limite estabelecido pela resolução CONAMA $357 / 05$

\section{CONCLUSÕES}

Os resultados obtidos ao longo do lago mostram que a água apresenta uma qualidade aceitável, uma vez que os parâmetros não conservativos estão dentro do valores de referência, e os parâmetros de químicos totais, quando estão acima dos limites da legislação têm forte influência da estrato rochoso do Grupo Bambuí, salvo exceção do boro que apresenta valores decorrentes de possível influência antrópica, entretanto de forma muito pontual no lago.

\section{AGRADECIMENTOS}

O trabalho foi possível graças ao auxílio e apoio do ICMBio que forneceu hospedagem de campo no alojamento da Estação Ecológica Pirapitinga dentro da barragem de Três Marias. Além do abrigo, o ICMBio disponibilizou um
O resultado positivo, possivelmente decorre do alto volume de água represado o que confere à área de estudo um grande poder de dissolução. Ou ainda, do fato da principal atividade da área ser de silvicultura. De qualquer forma, já está em curso pesquisa analítica dos mesmo parâmetros para verificar a influência climática sobre a qualidade da água, com levantamento de dados na estação chuvosa ou ainda para verificar se é possível atestar se houve influência do rejeito da barragem da mina do feijão.

barco e um funcionário para auxiliar na coleta de amostra. O trabalho foi realizado com apoio da Coordenação de Aperfeiçoamento de Pessoal de Nível Superior - Brasil (CAPES) Código de Financiamento 001. 

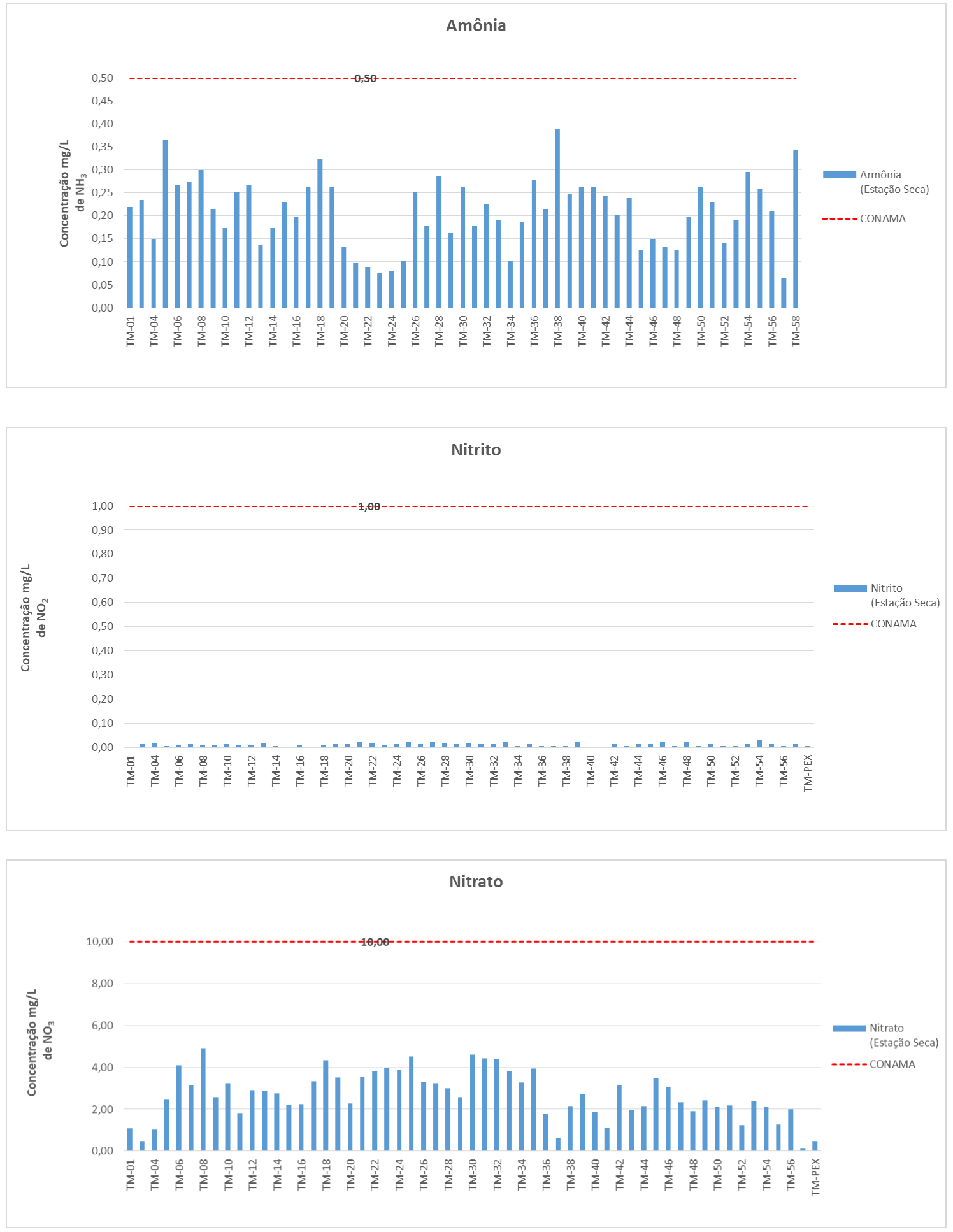

Figura 15 Gráficos com os valores medidos para Amônia, Nitrito e Nitrato - em vermelho destaca-se os limites estabelecido pela resolução CONAMA 357/05 

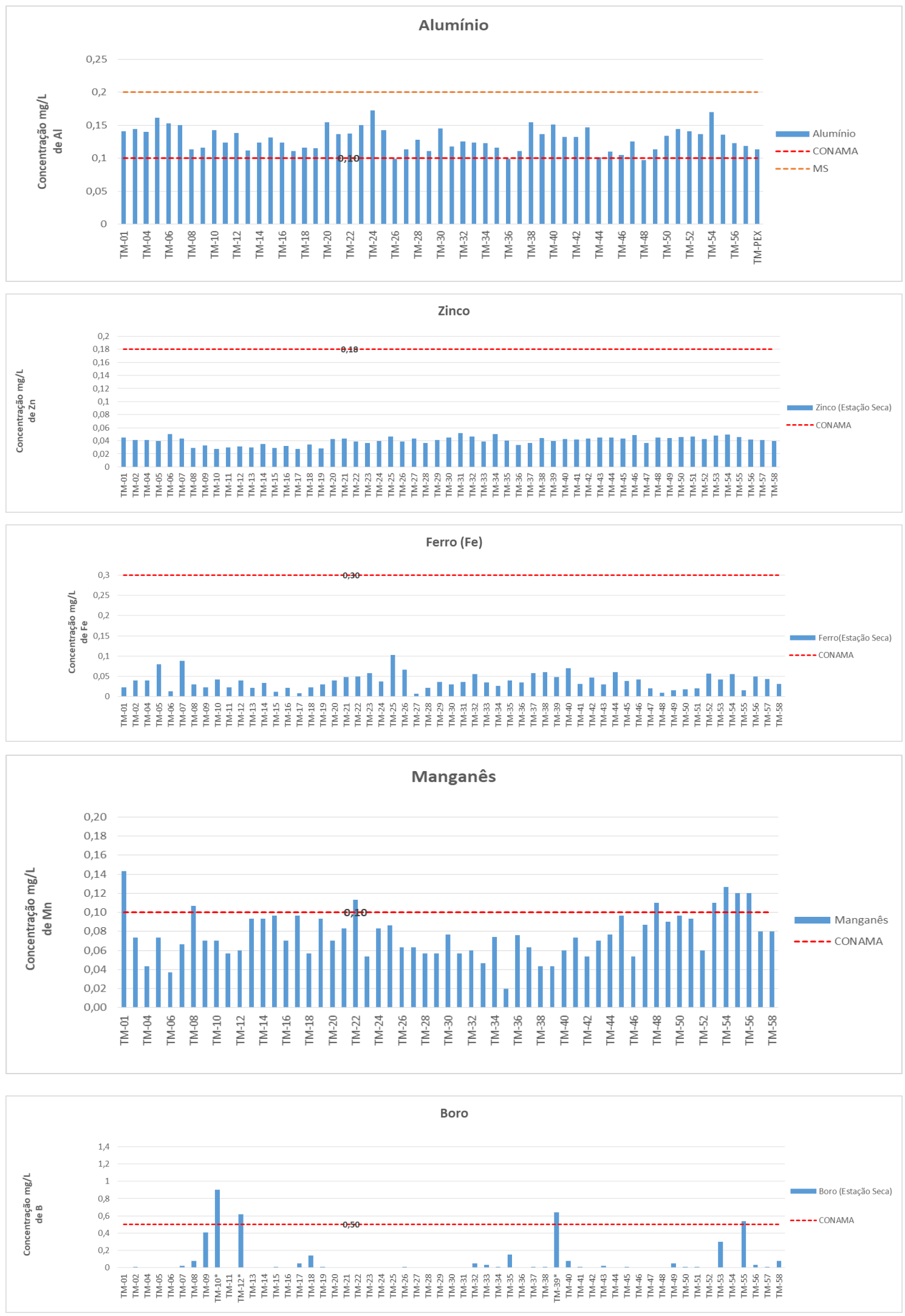

Figura 16 Gráficos com os valores medidos para Alumínio, Zinco, Ferro Manganês e Boro, em vermelho destaca-se os limites estabelecido pela resolução CONAMA 357/05 


\section{REFERÊNCIAS}

ANA - AGÊNCIA NACIONAL DE ÁGUAS. Relatório e mapa hidrográfico da bacia do Rio São Francisco. Brasília -DF: ANA. Disponível em: <http://www.ana.gov.br/>. Acesso em: 20 de maio 2019

BAIRD, C., RECIO, M. A. L., CARRERA, L. C. M., GRASSI, M.T. Química Ambiental. Porto Alegre: Bookman, 2008.

CBSHF - COMITÊ DA BACIA HIDROGRÁFICA DO RIO SÃO FRANCISCO. Plano de recursos hídricos 2016-2025. CBHSF Brasília, 2016.

CETESB - COMPANHIA AMBIENTAL DE ESTADO DE SÃO PAULO. Significado ambiental e sanitário das variáveis de qualidade. São Paulo - SP. 2017. 46 p.

COSTA, R. D., SILVA, R.R., KNAUER, L. G., PREZOTTI, F. P. S., DE PAULA, F. L., DUARTE, F. D., TEIXEIRA,L. F. Mapa Geológico, folha Três Marias - SE.23-Y-B-III. Escala 1:100000. In: Projeto Alto Paranaíba. Belo Horizote: CODEMIG, 2011.

BAGGIO, H. Contribuições naturais $e$ antropogênicas para a concentração $e$ distribuição de metais pesados em água superficial e sedimentos de corrente na Bacia do Rio do Formoso, município de Buritizeiro$M G$. UFMG. Belo Horizonte. Tese de Doutorado. 2008.

FRAGOSO, D. G. C; UHLEIM, A.; SANGLARD, J. C. D.; SUCKAU, G. L.; GUERZONI, H. T. G.; FARIA, P.H. Geologia dos grupos bambuí, areado e mata da corda na folha presidente olegário (1:100.000), mg: registro deposicional do neoproterozóico ao neocretáceo da bacia do são francisco. Geonomos, 19(1), 28-38, 2011.

GONCHARUK, V. V.; BAGRII, V. A.; MEL'NIK, L. A.; CHEBOTAREVA, R. D.; BASHTAN, S. YU. The use of redox potential in water treatment processes. J. Water Chem. Techno, 32(1), 1-9, 2010.

IGLESIAS, M.; UHLEIN, A. Estratigrafia do Grupo Bambuí e coberturas fanerozóicas no vale do rio São Francisco, norte de Minas Gerais. Braz. J. Geol. 39(2), 256-266, 2009.

IBGE - Instituto Brasileiro de Geografia e Estatística. Censo Demográfico 2010, Brasília DF: IBGE. Disponível em: < https://www.ibge.gov.br/>. Acesso em: $20 \mathrm{de}$ maio 2019

OLIVEIRA, M. R. DE. Investigações da contaminação por metais pesados da água e do sedimento de corrente nas margens do Rio São Francisco e Tributários, a jusante da represa da CEMIG, no município de Três Marias, Minas Gerais. 150 p. Tese de Doutorado UFMG. Belo Horizonte. 2007.

OLIVEIRA, M. R. DE; HORN, A. H. Comparação da concentração de metais pesados nas águas do rio São Francisco em Três Marias, desde 1991 até hoje, relacionando a atuação da CMM-Três Marias. Geonomos. 14(2), 55-63, 2006.

PARRON, L. M.; MUNIZ, D. H. DE F.; PEREIRA, C. M. Manual de procedimentos de amostragem e análise físico-química de água. Portal Embrapa. Embrapa Florestas, , 2011. Disponível em: $<$ https://www.embrapa.br/busca-depublicacoes/-/publicacao/921050/manual-deprocedimentos-de-amostragem-e-analise-fisicoquimica-de-agua >. Acesso em: 24 jul. 2019

RIBEIRO, E. V. Avaliação da qualidade da água do Rio São Francisco no segmento entre Três Marias e Pirapora - MG: metais pesados e atividades antropogênicas. 196 p. Dissertação de Mestrado. UFMG. Belo Horioznte.2010.

RICE, E. W.; AMERICAN PUBLIC HEALTH ASSOCIATION (EDS.). Standard methods for the examination of water and wastewater. Washington, DC: American Public Health Association, 22nd ed. 2012.

TRINDADE, W. M. Concentração e distribuição de metais pesados em sedimentos do Rio São Francisco entre Três Marias e Pirapora/MG: fatores naturais $e$ antrópicos. $111 \mathrm{p}$. Dissertação de Mestrado. UFMG. Belo Horizonte. 2010.

VON SPERLING, M. Estudo e modelagem da qualidade da água de rios. 2. ed. Belo Horizote: Editora UFMG,. v. 7. 2014a

VON SPERLING, M. Introdução à qualidade das águas e ao tratamento de esgotos. 4. ed. Belo Horizote: Edtora UFMG, v. 12014 b. 